\title{
Two new sacrolide-class oxylipins from the edible cyanobacterium Aphanothece sacrum
}

\author{
Naoya Oku${ }^{1}$, Sayaka Hana ${ }^{1}$, Miyako Matsumoto ${ }^{1}$, Kohsuke Yonejima ${ }^{1}$, Keijiroh Tansei ${ }^{2}$, Yasuhiro Isogai ${ }^{1}$ \\ and Yasuhiro Igarashi ${ }^{1}$
}

The Journal of Antibiotics (2017) 70, 708-709; doi:10.1038/ja.2017.32; published online 8 March 2017

Tradition of eating cyanobacteria is seen in the coastal area of Lake Chad, east and southeast Asian countries, and among Peruvian highlanders. ${ }^{1}$ In Japan, consumption of Nostoc commune, N. verrucosum and Aphanothece sacrum ('suizenji-nori' in Japanese) has been reported, only the last of which continues on a commercial basis. ${ }^{2}$ Because cyanobacteria are known as a prolific source of bioactive secondary metabolites, ${ }^{3}$ edible but less investigated species hold promise for new drug leads.

As part of our program to evaluate the biomedical potential of edible cyanobacteria, we examined the ethanolic extract of $A$. sacrum and discovered sacrolide $\mathrm{A}$ as an antimicrobial principle. ${ }^{2}$ It belongs to the oxylipin class metabolites, which are enzymatically or chemically derived fatty acid peroxidation products, ${ }^{4}$ and from cyanobacteria only four precede it which are as follows: malyngic acid, ${ }^{5}$ mueggelone, ${ }^{6}$ $(9 R, 10 E, 12 Z, 15 Z)$-octadecatrienoic acid $^{7}$ and $(9 R, 10 E, 12 Z)-$ octadecadienoic acid. ${ }^{7}$ Although oxylipins are known to function as intra- and interspecific signaling molecules or as microbicides in plants, ${ }^{4}$ their role in prokaryotes is practically unknown. To gain

a

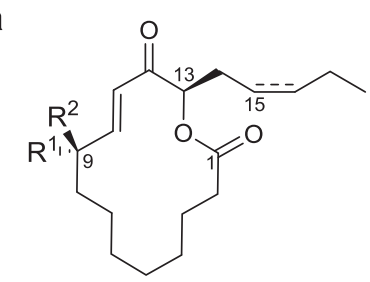

$$
\begin{aligned}
& \begin{array}{ll}
R^{1} & R^{2}
\end{array} \\
& \text { sacrolide } \mathrm{A}: \mathrm{H} \quad \mathrm{OH} \quad \Delta^{15} \\
& 1: \mathrm{OH} \quad \mathrm{H} \quad \Delta^{15}
\end{aligned}
$$

b

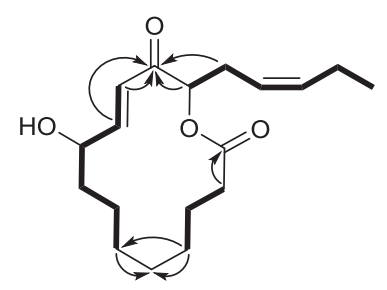

Figure 1 (a) Structure of sacrolide A, 9-epi-sacrolide A (1) and 15,16-dihydrosacrolide A (2). (b) Selected COSY/TOCSY (bold lines) and HMBC (arrows) correlations for 1 . further insights into the function and structural diversity of prokaryotic oxylipins, congeners of sacrolide A (Figure 1) were pursued in $A$. sacrum, which resulted in the isolation of two new congeners, 9-epi-sacrolide A (1) and 15,16-dihydrosacrolide A (2).

The ethanolic extract of the algal colonies was partitioned between dichloromethane and $60 \%$ aqueous $\mathrm{MeOH}$, and the former between $n$-hexane and $90 \%$ aqueous $\mathrm{MeOH}$. The antimicrobial principles in the latter layer were purified by open column chromatography on silica gel, gel filtration on Sephadex LH-20, normal phase HPLC on silica gel to yield crude sacrolide A, as previously described. NMR-based examination of the peaks eluting before and after sacrolide A revealed the presence of its congeners, which prompted further purification of both fractions by reversed-phase HPLC to yield 1 and 2 , respectively.

Compound $\mathbf{1}$ has the same molecular formula as sacrolide A $\left(\mathrm{C}_{18} \mathrm{H}_{30} \mathrm{O}_{4}\right)$ as evidenced by a molecular ion peak at $\mathrm{m} / \mathrm{z} 331.1864$ $\left([\mathrm{M}+\mathrm{Na}]^{+}, \quad \mathrm{C}_{18} \mathrm{H}_{28} \mathrm{NaO}_{4}, \Delta-1.6 \mathrm{mmu}\right)$ in the HRESITOF-MS analysis. ${ }^{2}$ The ${ }^{1} \mathrm{H}$ NMR spectrum of 2 (Supplementary Table S4) assorted all signals from sacrolide $\mathrm{A},{ }^{2}$ some of which though shifted upfield and changed shape, indicating that $\mathbf{1}$ is either a diastereomer or transesterified isomer of sacrolide A. Indeed, interpretation of a full set of NMR spectra supported this idea: the presence of spinsystems $\mathrm{H}_{2} 2$ / $\mathrm{H}_{2} 3 / \mathrm{H}_{2} 4, \mathrm{H}_{2} 6 / \mathrm{H}_{2} 7 / \mathrm{H}_{2} 8 / \mathrm{H} 9 / \mathrm{H} 10 / \mathrm{H} 11$ and $\mathrm{H} 13 / \mathrm{H}_{2} 14 / \mathrm{H} 15 / \mathrm{H}_{16} / \mathrm{H}_{2} 17 /$ $\mathrm{H}_{3} 18$ was evident from the sequence of COSY and TOCSY crosspeaks (Figure 1); the $10 E$ and $15 Z$ geometries from ${ }^{3} J_{\mathrm{H} 10-\mathrm{H} 11}=15.8 \mathrm{~Hz}$ and ${ }^{3} J_{\mathrm{H} 15-\mathrm{H} 16}=\sim 10 \mathrm{~Hz}$; placement of carboxylate at $\mathrm{C} 1$ from $\mathrm{HMBC}$ correlations $\mathrm{H} 2 / \mathrm{C} 1\left(\delta_{\mathrm{H}} 2.56 / \delta_{\mathrm{C}} 172.8\right.$ Figure 1$)$; connectivity between C4 and C6 through C5 from HMBC correlations H4/C5 $\left(\delta_{\mathrm{H}} 1.32 / \delta_{\mathrm{C}}\right.$ $27.0), \mathrm{H} 4 / \mathrm{C} 6\left(\delta_{\mathrm{H}} 1.32 / \delta_{\mathrm{C}} 25.4\right)$ and $\mathrm{H} 6 / \mathrm{C} 5\left(\delta_{\mathrm{H}} 1.36 / \delta_{\mathrm{C}} 27.0\right)$; interruption of ketone between $\mathrm{C} 11$ and $\mathrm{C} 13$ from $\mathrm{HMBC}$ correlations $\mathrm{H} 11 / \mathrm{C} 12\left(\delta_{\mathrm{H}} 6.47 / \delta_{\mathrm{C}} 196.8\right)$ and $\mathrm{H} 13 / \mathrm{C} 12\left(\delta_{\mathrm{H}} 5.13 / \delta_{\mathrm{C}} 196.8\right)$. Thus, an acyloxy backbone with an $\alpha, \beta$-unsaturated- $\alpha^{\prime}, \gamma$-ketodiol motif, present in sacrolide A, was assembled. Formation of an ester linkage between $\mathrm{C} 1$ and $\mathrm{C} 9$ was denied by the fact that $\mathbf{1}$ and sacrolide A both gave the same oxidation product (see below), leaving

${ }^{1}$ Biotechnology Research Center and Department of Biotechnology, Toyama Prefectural University, Toyama, Japan and ${ }^{2}$ Suizenjinori-Hompo Tanseidoh, Kumamoto, Japan Correspondence: Professor Y Igarashi, Biotechnology Research Center and Department of Biotechnology, Toyama Prefectural Univ., 5180 Kurokawa, Imizu, Toyama 939-0398, Japan.

E-mail: yas@pu-toyama.ac.jp

This paper is dedicated to Professor Dr Satoshi Ōmura for his Nobel Prize in Physiology or Medicine 2015.

Received 17 October 2016; revised 20 January 2017; accepted 5 February 2017; published online 8 March 2017 
diastereomeric structure as the only possibility. Difference in a coupling constant between $\mathrm{H} 9$ and $\mathrm{H} 10(1,7.6 \mathrm{~Hz}$; sacrolide A, $4.7 \mathrm{~Hz}$ ) and an inverted intensity of a pair of NOESY correlations H9/H10 and H9/H11 (1, weak and strong; sacrolide A, strong and weak: see S14 and S15) endorsed this assignment.

To specify which of the two stereocenters (C9 or C13) is epimerized, 1 and sacrolide A were separately oxidized with $\mathrm{MnO}_{2}$ and $\mathrm{CD}$ spectra of the resulting diketone products 3 was compared, which retain the configuration of $\mathrm{C} 13$ from the mother compounds (Supplementary Figure S5). Because both 3 exhibited a weak but obvious negative CD Cotton effect, they were enantiomerically identical. Considering the $(9 R, 13 R)$ configuration of sacrolide A, 1 was concluded to have a $(9 S, 13 R)$ configuration.

Compound 2 gave a molecular ion at $\mathrm{m} / z 333.2002[\mathrm{M}+\mathrm{Na}]^{+}$ $\left(\mathrm{C}_{18} \mathrm{H}_{30} \mathrm{O}_{4}, \Delta-3.4 \mathrm{mmu}\right)$ in an ESITOFMS measurement, which is larger by two hydrogens than sacrolide A. The ${ }^{1} \mathrm{H}$ NMR spectrum of 2 was reminiscent of sacrolide $\mathrm{A}$, as represented by the keto-conjugated E-olefin $\left(\mathrm{H} 10: \delta_{\mathrm{H}} 6.95 \mathrm{dd}, J=4.7\right.$ and $15.8 \mathrm{~Hz}, \mathrm{H} 11: \delta_{\mathrm{H}} 6.57 \mathrm{dd}$, $J=1.4$ and $15.9 \mathrm{~Hz}$, Supplementary Table S6) and adjacent two oxymethine (H9: $\delta_{\mathrm{H}} 4.50 \mathrm{~m}, \mathrm{H} 13: \delta_{\mathrm{H}} 5.13 \mathrm{dd}, J=6.7$ and $\left.6.9 \mathrm{~Hz}\right)$ signals. However, signals for two olefinic methines $\left(\delta_{\mathrm{H}} 5.30\right.$ and $\delta_{\mathrm{H}}$ 5.54) and allylic methylenes $\left(\delta_{\mathrm{H}} 2.61,2.56\right.$, and 2.06) were missing, implying the saturation of the side chain in 2 . This assignment was confirmed by HMBC correlations from a methyl proton $\left(\mathrm{H} 18: \delta_{\mathrm{H}}\right.$ $0.89)$ to two aliphatic carbons $\left(\mathrm{C} 16: \delta_{\mathrm{C}} 31.4\right.$ and C17: $\left.\delta_{\mathrm{C}} 22.4\right)$. A closer similarity of the ${ }^{1} \mathrm{H}$ NMR chemical shift values and coupling constants to those of sacrolide A, rather than of $\mathbf{1}$, verified the same conformation and relative configuration to sacrolide A. The positive sign of the optical rotation was also the same $\left(2:[\alpha]_{D}{ }^{24.1}+4.9, c 0.038\right.$ : sacrolide $\mathrm{A}:[\alpha]_{\mathrm{D}}^{24.1}+24.5$, c 0.392 , both in $\left.\mathrm{MeOH}\right)$, supporting the $(9 R, 13 R)$-absolute stereochemistry. Thus, the structure of 2 was concluded to be a 15,16-dihydro derivative of sacrolide A.

Compound 1 was inactive against four microorganisms sensitive to sacrolide A (Staphylococcus aureus, Streptomyces lividans, Saccharomyces cerevisiae and Penicillium chrysogenum) at the tested concentration range, while 2 was marginally active against eumycetes (Table 1). These results demonstrate that the $9 S$-hydroxy group is crucial for the antimicrobial activity of sacrolide A but unsaturation at the aliphatic tail is less so against eumycetes. A substantial number of oxylipins bear an $\alpha, \beta$-unsaturated ketone motif and are known to disable a certain set of redox-controlled proteins by modifying the active site sulfhydryl groups. ${ }^{8,9}$ Sacrolide A belongs to the same oxylipin class, but loss of the activity upon epimerization of C9 suggests that it is more of a target-specific inhibitor than promiscuous Michael acceptor. ${ }^{10}$

Conservation of an S-configuration at C13 among sacrolide A, 1 and 2 implies that hydroxylation of this carbon is an enzymatic process. In contrast, variation in the chirality of C9 carbinol and the degree of unsaturation at $\mathrm{C} 15$ is allowed, underpinning a
Table 1 Comparison of the antimicrobial activity among sacrolide A congeners ( $\mathrm{MIC} \mathrm{\mu g} \mathrm{ml}^{-1}$ )

\begin{tabular}{lccc}
\hline Microbe & 1 & 2 & Sacrolide A \\
\hline $\begin{array}{l}\text { Gram-positive } \\
\quad \text { Staphylococcus aureus }\end{array}$ & $8.0 \leqq$ & $8.0 \leqq$ & 0.5 \\
$\quad$ Streptomyces lividans & $8.0 \leqq$ & $8.0 \leqq$ & 1.0 \\
Yeast & & & \\
$\quad$ Saccharomyces cerevisiae & $8.0 \leqq$ & 8.0 & 8.0 \\
$\begin{array}{l}\text { Fungus } \\
\quad \text { Penicillium chrysogenum }\end{array}$ & $8.0 \leqq$ & 8.0 & 1.0 \\
\hline
\end{tabular}

Abbreviation: MIC, minimum inhibitory concentration.

non-enzymatic formation of $\alpha, \beta$-unsaturated- $\gamma$-ketol from 12,13 allene oxide precursors (Supplementary Scheme S7). ${ }^{11}$

\section{CONFLICT OF INTEREST}

The authors declare no conflict of interest.

\section{ACKNOWLEDGEMENTS}

This work was supported in part by President's Fund Initiative 2014 (Science for Local Community) at Toyama Prefectural University.

1 Oku, N., Yonejima, K., Sugawa, T. \& Igarashi, Y. Identification of the n-1 fatty acid as an antibacterial constituent from the edible freshwater cyanobacterium Nostoc verrucosum. Biosci. Biotechnol. Biochem. 78, 1147-1150 (2014).

2 Oku, N., Matsumoto, M., Yonejima, K., Tansei, K. \& Igarashi, Y. Sacrolide A, a new antimicrobial and cytotoxic oxylipin macrolide from the edible cyanobacterium Aphanothece sacrum. Beilstein J. Org. Chem. 10, 1808-1816 (2014).

3 Leão, P. N., Engene, N., Antunes, A., Gerwick, W. H. \& Vasconcelos, V. The chemical ecology of cyanobacteria. Nat. Prod. Rep. 29, 372-391 (2012).

4 Mosblech, A., Feussner, I. \& Heilmann, I. Oxylipins: structurally diverse metabolites from fatty acid oxidation. Plant Physiol. Biochem. 47, 511-517 (2009).

5 Cardellina, J. H. II \& Moore, R. E. Malyngic acid, a new fatty acid from Lyngbya majuscula. Tetrahedron 36, 993-996 (1980).

6 Papendorf, O., König, G. M., Wright, A. D., Chorus, I. \& Oberemm, A. Mueggelone a novel inhibitor of fish development from the fresh water cyanobacterium Aphanizomenon flos-aquae. J. Nat. Prod. 60, 1298-1300 (1997).

7 Murakami, N., Shirahashi, H., Nagatsu, A. \& Sakakibara, J. Two unsaturated $9 R$-hydroxy fatty acids from the cyanobacterium Anabaena flos-aquae $f$. flos-aquae. Lipids 27, 776-778 (1992).

8 Farmer, E. F. \& Davoine, C. Reactive electrophile species. Curr. Opin. Plant Biol. 10, 380-386 (2007).

9 Mueller, M. J. \& Berger, S. Reactive electrophilic oxylipins: pattern recognition and signaling. Phytochemistry 2009, 1511-1512 (2009).

10 Robert F. Bruns, R. F. \& Watson, I. A. Rules for identifying potentially reactive or promiscuous compounds. J. Med. Chem. 55, 9763-9772 (2012).

11 Andreou, A., Brodhun, F. \& Feussner, I. Biosynthesis of oxylipins in non-mammals. Prog. Lipid Res. 48, 148-170 (2009).

Supplementary Information accompanies the paper on The Journal of Antibiotics website (http://www.nature.com/ja) 